\title{
Analysis and Evaluation of Effect of Manganese Content on Properties of EN AC 46000 Aluminum Alloy
}

\author{
Martyna Pasternak*, Marcin Brzeziński $\oplus^{\circledR}$, Gabriela Piwowarczyk \\ AGH University of Science and Technology, Faculty of Foundry Engineering, Reymonta 23, 30-059 Krakow, Poland \\ *e-mail:martpiw@gmail.com
}

Received: 1 March 2019/Accepted: 23 March 2019/Published online: 31 March 2019

This article is published with open access by AGH University of Science and Technology Press

\begin{abstract}
This article is the effect of industrial work and many surveys in the one of the Polish foundries that specialize in aluminum alloys. The main goal of our explorations is to evaluate the influence of manganese on Al-Si alloy properties. In die-cast alloys, it is recommended to use larger amounts of iron to reduce the impact on the pressure chamber and mold. Manganese neutralizes the harmful effect of iron by changing the morphology of the separated brittle ferrous phases. The unfavorable form of the iron-containing phases in the form of long needles changes into the forms of fine compact crystals, which are less harmful to the mechanical properties. Nowadays, the main client requirement is to obtain the right parameters at the best price. Specifically, the customer is in the automotive industry, where new technologies provide a connection between the high quality and low weight of car parts [1-3].
\end{abstract}

\section{Keywords:}

aluminum alloy, pressure casting, manganese, strength of material

\section{INTRODUCTION}

The introduction of a completely new alloy often involves changes in the casting process, purchases of new machinery (or the modernization of the existing devices), training employees, and changes in occupational health and safety conditions. Not only do the casting parameters change, but they are also sometimes further processed. Attention should also be paid to the ratio of the price of alloying elements to the properties obtained by their use. These aspects lead to the correction of existing processes, where sometimes a small change can have great beneficial effects.

The impact of alloying elements are as follows.

- Copper - increases tensile strength and hardness as well as improves machinability and resistance to heat loads. At the same time, it reduces elongation and deteriorates corrosion resistance. The change of properties is caused by the strengthening of the $\alpha(\mathrm{Al})$ phase.

- Zinc - similar effects as with copper, but its content within a range of $0.05-2 \%$ classifies it as an impurity, while it is treated as an alloying element above $5 \%$.

- Magnesium - in liquid metal, it combines with silicon to form Mg2Si compounds. These compounds are characterized by variable solubility in the solid solution $\alpha(\mathrm{Al})$, which allows the use of heat treatment in castings made of AlSi alloys. This increases the properties of castings such as their hardness, tensile strengths and yield strengths.
- Nickel - has a stronger effect than copper; its effect is noticeable in the case of changes in the mechanical properties of castings operating at elevated temperatures by preventing their deterioration.

- Silicon - the basic component of silumins; it has a significant influence on their casting properties. The best results are obtained with the composition of silumins close to eutectic. An increase in its compactness is connected with a decrease in the value of the thermal expansion coefficient of silumens, which is very important in the case of castings operating at elevated temperatures with high requirements for dimensional stability.

- Iron, tin, lead, and zinc are the main impurities of AlSi alloys, and (as mentioned earlier) Zn can be treated as an alloying element in relevant alloying contents.

- Iron in alloys occurs in the form of coniferous crystals of a very brittle Al4Si2Fe compound causing a decrease in mechanical properties, especially the plastic properties and impact strength of castings. The addition of $0.3-0.45 \% \mathrm{Mn}$ transforms the inclusions of the phase that contains iron into the form of small compact polygonal crystals, which no longer have a negative effect on the strength properties. In die-cast alloys, it is recommended to use larger amounts of iron in order to reduce the effect on the pressure chamber and mold. Higher iron contents therefore require the use of larger amounts of manganese. 
- Manganese - neutralizes the harmful effect of iron alloy impurities on their mechanical properties by changing the morphology of the separated brittle iron-containing phases. The unfavorable form of iron-containing phases in the form of long needles precipitate into small compact crystals, which are less harmful to mechanical properties. Manganese is also added in amounts of $0.2-0.5 \%$ in order to eliminate the negative effects caused by the presence of iron.

Density index - a value used to evaluate the relative content of a casting material. The density of a solidifying casting material is compared at atmospheric and reduced pressures, which is treated as a kind of vacuum. This is expressed by formula (1):

$$
\rho_{\text {cast }}=\frac{m_{s(\text { atm })}}{m_{s(a t m)}-m_{s(\text { water })}} \cdot \rho_{\text {water }}
$$

where:

$$
\begin{aligned}
m_{s(\text { atm })}- & \text { weight of casting material sample determined } \\
& \text { by method of weighing in ambient air; } \\
m_{s(\text { water })}- & \text { weight of casting material sample determined } \\
& \text { by method of weighing in water; } \\
\rho_{\text {water }}- & \text { water density at } 40^{\circ} \mathrm{C} \text { at pressure of } 1013.25 \mathrm{hPa} .
\end{aligned}
$$

Strengthening - the presence of free space in an alloy. This is a casting defect, which is mainly caused by gasification of the alloy in pressure castings. Porosity may have an influence on the decrease of a casting's strength, as the occurrence of porosity causes an increase of the stresses inside the casting, which results in exceeding the yield strength of the material and permanent deformation (which may lead to cracking). There is also the possibility of the so-called notch effect associated with pore geometry. This results in the weakening of the strength of castings at the place of its occurrence.

Shrinkage porosity is caused by a thermo-physical phenomenon consisting of a rapid increase in material volume during solidification. This defect observed on an optical microscope is cave-shaped, as shown in Figure 1.

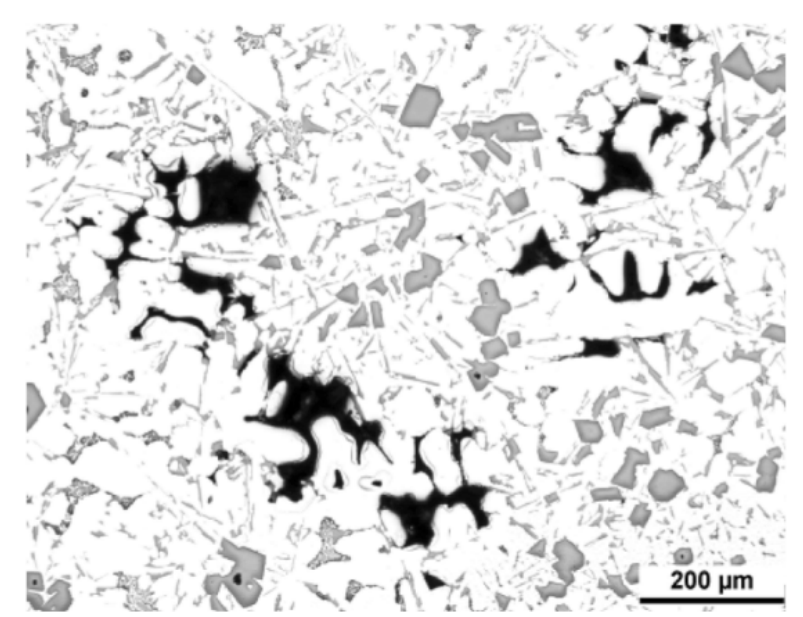

Fig. 1. Shrinkage porosity- microstructural image according to [4]

\section{EXPERIMENTAL}

The following tests were carried out at a pressure foundry specializing in aluminum alloys. The obtained results refer to the AK 93 alloy (Tab. 1). The high iron content in aluminum alloys, low strength properties of castings, and occurrence of leaks and cracks were the basis for tests on alloys with increased manganese contents.

Due to the need to maintain the continuity of work and to produce many different series of castings at the same time, the following aspects had to be considered:

- no possibility of sudden changes in the chemical composition of an alloy - the necessity of maintaining process continuity;

- compatibility of the metal chemical composition imposed by the standard EN AC-Al Si9Cu3(Fe) [5].

One of the most important parameters is the strengths of material - especially tensile strength. This parameter was the main indicator of the quality improvement relat-

\begin{tabular}{|c|c|c|c|c|c|c|c|c|c|c|}
\hline Alloy & $\mathbf{S i}$ & $\mathrm{Fe}$ & $\mathrm{Cu}$ & Mn & Mg & $\mathrm{Cr}$ & $\mathrm{Ni}$ & $\mathbf{Z n}$ & $\mathrm{Ti}$ & Al \\
\hline Nicromet EN AC 46000 & 8.71 & 0.88 & 2.19 & 0.471 & 0.31 & 0.056 & 0.045 & 0.89 & 0.037 & 86.3 \\
\hline $\begin{array}{c}\text { AK } 93 \\
\text { according to } \\
\text { EN AC-Al.Si9Cu3(Fe) }\end{array}$ & $8-11$ & $<1.3$ & $2-4$ & $<0.55$ & $0.05-0.55$ & $<0.15$ & $<0.55$ & $<1.2$ & $<0.25$ & - \\
\hline
\end{tabular}
ed to the increase of manganese content in the aluminum alloy. Additional tests were carried out, such as density index, chemical composition, and X-ray examinations.

Table 1

Chemical composition, \% [5] 
X-ray scanning is a good and quick way to show the porosity of a casting. Porosity can effect the strength of castings. This parameter causes an increase in stress inside the casting, which is connected to exceeding the yield point of the material and permanent deformations. In the end, it can lead to a part crack.

Standard EN AC-46000 AC-AlSi9CU3(FE) provides for a maximum manganese content of $0.55 \%$ (Tab. 1). Initially, a spectrometric analysis showed a $0.29 \%$ manganese content in the alloy, after which it was increased to $0.471 \%$ (Tab. 1). The higher content of this element was obtained by adding pigs (bought pieces of alloy) with an increased content of manganese to the alloy. The main problem was the required minimal content $(300 \mathrm{~kg}$ ) of metal in the furnace connected with the die-casting machine. It was not possible to completely empty this furnace and load a new batch; therefore, the chemical composition of the alloy was charged gradually by adding an alloy with a higher manganese content to the furnace. This method was aimed at a slow increase in the content of the element, which is shown in Figure 2. As can be seen, there were large fluctuations in the chemical composition among the successive attempts of the alloy, which is most likely related to the problem of mixing the new alloy introduced into the furnace with the one present earlier.
The increase in Mn content is associated with an increase in production costs, which are at the same time compensated by the smaller number of losses.

Parameters such as the density index, chemical composition, and porosity (X-ray) were examined on several samples with different contents of manganese. The samples were taken during the progressive increase of manganese content in the alloy; the following results refer to the samples with the initial Mn (0.29\%) and final Mn (0.47\%) contents.

The density index was tested using an MK 300 Electronic Density Index Balance, model MK 3000, harmonized with the EN 55011:2009, EN 55022:2010; EN 61 010-1:2010, EN 61000-6-1:2007, and EN 61000-6-2:2005 standards. The samples were cast into metal bowls and made in two versions: without refining and after refining. Argon was used as a refiner.

The chemical composition was checked using a SpectroMAXx spectrometer with Spark Analyser MX software. The porosity was detected with the use of X-rays. The examination takes place on the basis of the purchased standards, but they are significantly expanded for the needs of the company; each cast detail has its own catalogue of defects and sensitive places to be scanned.

The tensile strength was tested in accordance with the ISO 6892-1 standard [6]. The dimensions of the sample are shown in Figure 3.

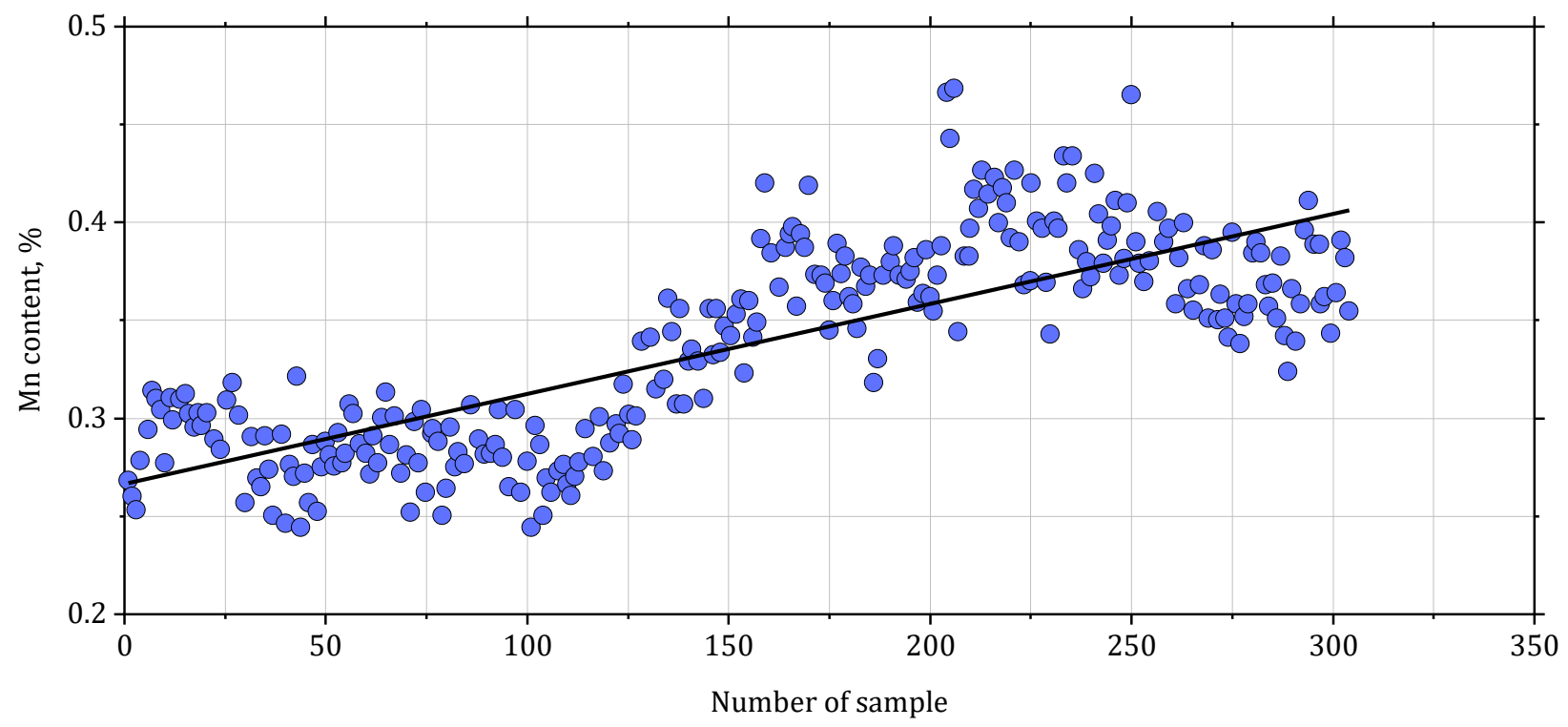

Fig. 2. Course of Mn content growth in subsequent tests of chemical composition

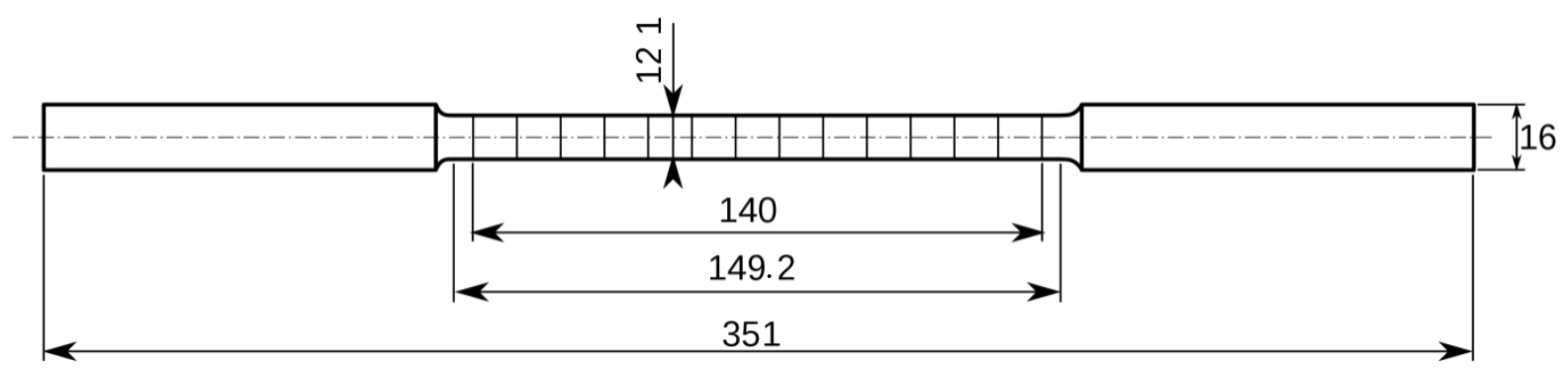

Fig. 3. Dimensions of sample for strength test [6, 7] 


\section{RESULTS}

Conducting research under industrial conditions was a long-term process. The introduced changes could not have a negative impact on the demands placed on the castings; therefore, they had to be done with great attention. As mentioned earlier, changes in the chemical composition of the cast alloy were related to the technological parameters of the casting machine (the minimum metal content of the furnace). During the introduction of new batches of metal into the machine, it was noticed that there are problems with mixing the filled alloy with the alloy that was previously there. Each time, the alloy is subjected to barbotage refining with the use of argon after it has been poured into the ladle and before being placed in a pressure machine.

Example photos of the microstructures for the initial and final contents of $\mathrm{Mn}$ in the alloy are shown in Figures 4 and 5. A fragment of an X-ray image is shown in Figure 6. It is a cast image made of an alloy with a high manganese content. The selected fragment is a sensitive area where leakage occurred. Small porosities are acceptable, as this element is impregnated to increase its tightness. In general, it is worth remembering that, in pressure castings, there are always small porosities associated with the specification of this type of casting.
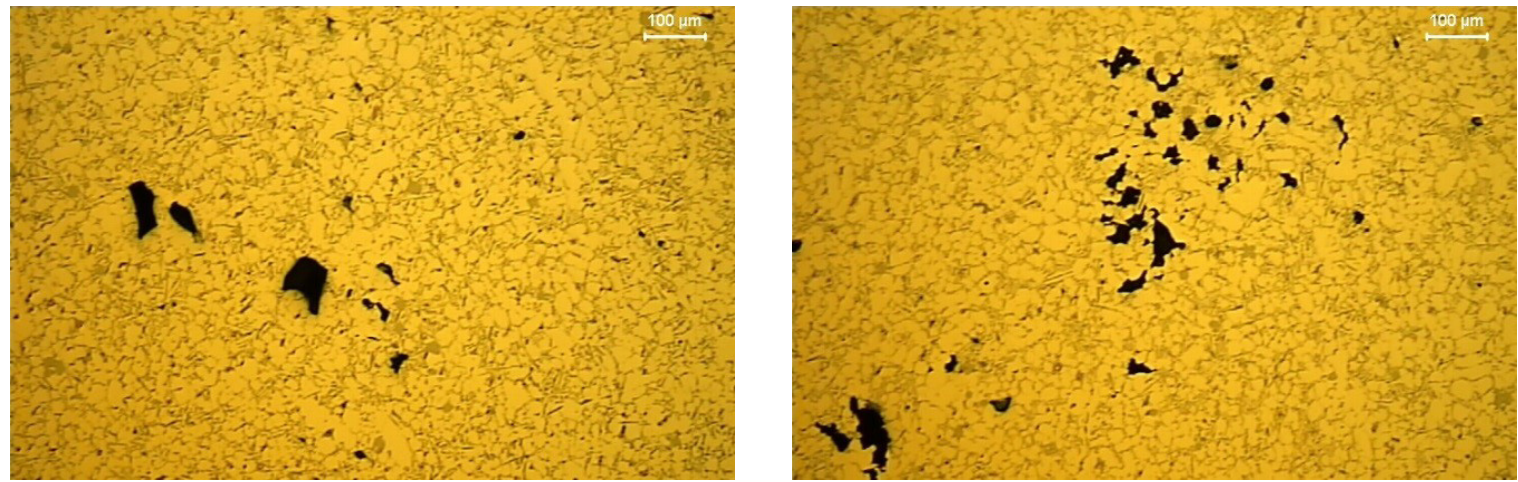

Fig. 4. Microstructure of casting made of alloy with initial Mn content (0.29\%)
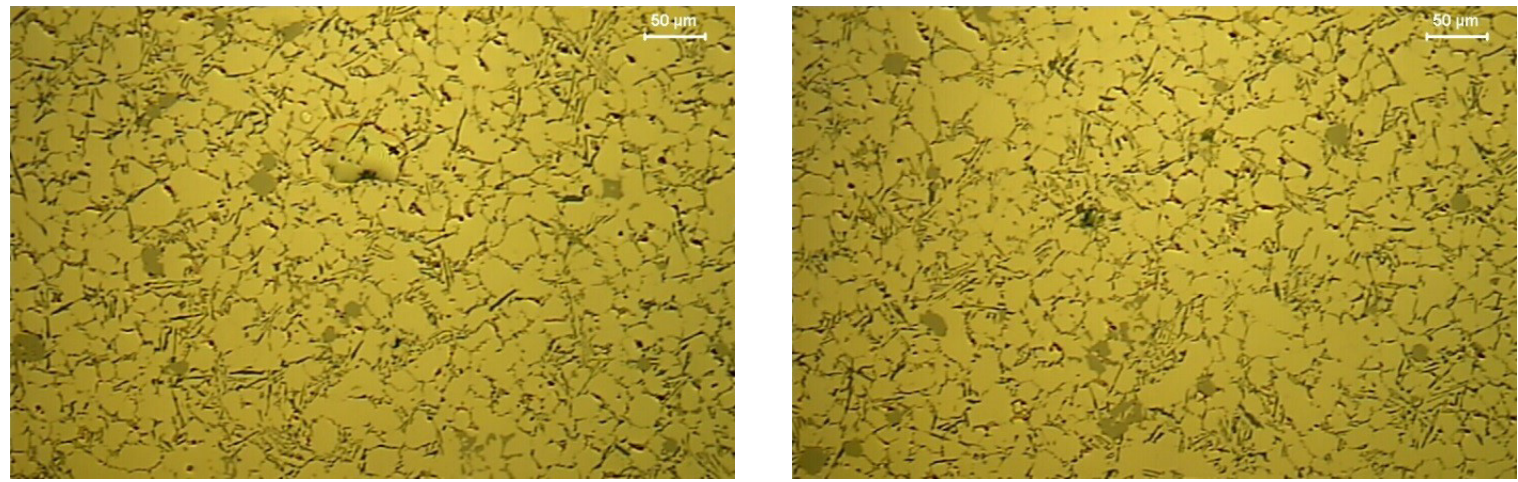

Fig. 5. Microstructure of casting made of alloy with increased Mn content (0.47\%)

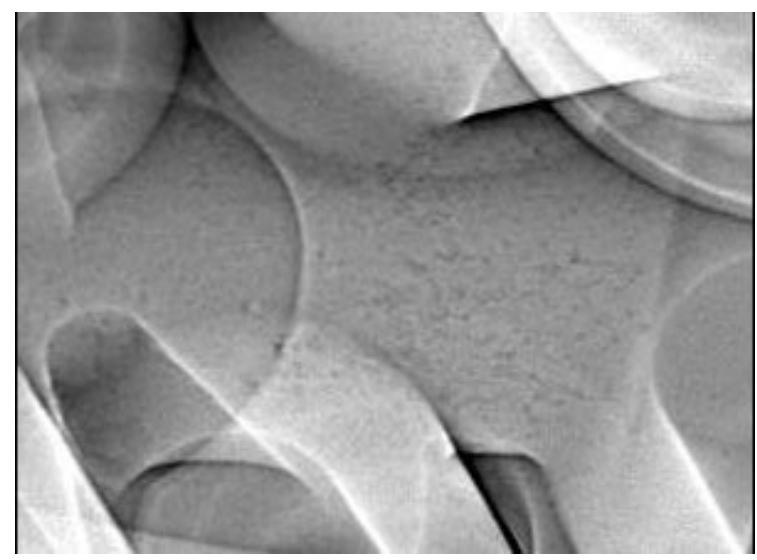

Fig. 6. Fragment of X-ray image 
Table 2 compares results of strength test of standard alloy and alloy with increased content of Mn. Table 3 shows the differences in the density index for standard alloy and alloy with increased Mn before and after refining.

Table 2

Strength values

\begin{tabular}{ccccc}
\hline \multirow{2}{*}{ Sample } & \multicolumn{2}{c}{$\boldsymbol{R}_{\boldsymbol{e}^{\prime}} \mathrm{MPa}$} & \multicolumn{2}{c}{$\boldsymbol{R}_{\boldsymbol{m}^{\prime}} \mathrm{MPa}$} \\
\cline { 2 - 5 } & $\begin{array}{c}\text { before } \\
\text { refining }\end{array}$ & $\begin{array}{c}\text { after } \\
\text { refining }\end{array}$ & $\begin{array}{c}\text { before } \\
\text { refining }\end{array}$ & $\begin{array}{c}\text { after } \\
\text { refining }\end{array}$ \\
\hline $\begin{array}{c}\text { Standard } \\
\text { alloy }\end{array}$ & 176 & 185 & 206.5 & 214.8 \\
\hline $\begin{array}{c}\text { Alloy } \\
\text { with increased } \\
\text { content of Mn }\end{array}$ & 222 & 205 & 231.8 & 244.5 \\
\hline
\end{tabular}

Table 3

Density index values

\begin{tabular}{ccc}
\hline \multirow{2}{*}{ Sample } & \multicolumn{2}{c}{ Density index, \% } \\
\cline { 2 - 3 } & before refining & after refining \\
\hline $\begin{array}{c}\text { Standard } \\
\text { alloy }\end{array}$ & 6.60 & 0.64 \\
\hline $\begin{array}{c}\text { Alloy } \\
\text { with increased } \\
\text { content of Mn }\end{array}$ & 3.73 & 0.54 \\
\hline
\end{tabular}

\section{CONCLUSIONS}

The obtained results indicated the correctness of our initial hypotheses. It has been discovered that the increase content of manganese affects the following:

- improves strength properties of castings (Tab. 2);

- improves casting microstructures;

- improves density index values (Tab. 3);

- increases tightness of castings;

- stabilizes quality of castings.

The proposed change in production is related only to the input introduced into the melting furnace. The purchase of alloys with increased manganese contents is connected with slightly higher costs, which will be compensated by reducing the shortages.

\section{REFERENCES}

[1] Poniewierski Z. (1989). Krystalizacja, struktura i właściwości siluminów. Warszawa: Wydawnictwo Naukowo-Techniczne.

[2] Poniewierski Z. (1966). Modyfikacja siluminów. Warszawa: Wydawnictwo Naukowo-Techniczne.

[3] Górny Z., Sobczak J. (2005). Nowoczesne tworzywa odlewnicze na bazie metali nieżelaznych. Kraków: ZA-PIS.

[4] BDG standard - P202 "Volume Deficits of Casting Made from Aluminium, Magnesium, and Zinc Casting Alloys"

[5] EN AC-46000 AC-AlSi9CU3(FE) (2010)

[6] ISO 6892-1; First edition 2009-08-15

[7] PN-EN ISO 6892-1 